\title{
Evaluation of 4 different bone graft substitutes and autogenous bone grafting in root-end resection osteotomies after retrograde root-filling with Intermediate Restorative Material (IRM): An experimental study in dogs
}

\author{
Dan-Åke Wälivaara*, Peter Abrahamsson \\ Maxillofacial Unit, Halmstad Hospital Halland, Halmstad, Sweden \\ Email: * dan-ake.valivaara@,regionhalland.se
}

Received 30 January 2013; revised 25 March 2013; accepted 8 April 2013

Copyright (C) 2013 Dan-Åke Wälivaara, Peter Abrahamsson. This is an open access article distributed under the Creative Commons Attribution License, which permits unrestricted use, distribution, and reproduction in any medium, provided the original work is properly cited.

\begin{abstract}
Purpose: To investigate the periapical tissue response after root end filling with intermediate restorative material (IRM) and filling of the root-end resection bone defects with autogenous bone or a bone graft substitute in comparison to empty controls. Materials and Methods: Vital roots of the second, third and fourth mandibular premolars in six healthy mongrel dogs were apectomized. The root canals were prepared and sealed with IRM following a standardized surgical procedure. The resection bone defects were either filled with autogenous bone (PB) or one of the bone graft substitutes; CERAMENT ${ }^{\mathrm{TM}} \mid$ BONE VOID FILLER, ChronOS ${ }^{\circledR}$, Tigran ${ }^{\mathrm{TM}}$ PTG, Easygraft ${ }^{\circledR}$ CLASSIC or left empty. After 120 days the animals were sacrificed and the specimens were analyzed radiologically and histologically. Kruskal-Wallis and Mann-Whitney tests were performed for statistical evaluation. Results: 34 sections were analyzed histologically. The evaluation revealed a variation in the outcome amongst the tested options, regarding reestablishment of the periapical bone healing and inflammatory infiltration in the sections. According to the tested variables, there was no statistical significant difference between the materials when comparing all groups as a whole. When comparing individual materials to each other there was statistical differences among some of the tested materials. Conclusion: The healing outcome after periapical surgery of a five-wall resection defect could not be increased by infill with autogenous bone or bone graft substitutes. The most important factor for the healing outcome in
\end{abstract}

\footnotetext{
"Corresponding author.
}

periapical surgery is the quality of the root-end sealing. The healing outcome after some of the tested bone substitutes, might be improved by longer healing time.

Keywords: Bone Graft Substitutes; Periapical Surgery; Autogenous Bone; Intermediate Restorative Material

\section{INTRODUCTION}

Periapical surgery is performed in case of unsuccessful healing after conventional endodontic therapy. In suitable cases the surgery should first be preceded by a revision of the orthograde root-filling. The primary goal of a periapical surgery procedure including a root-end resection and performance of a retrograde root end filling is to seal the root canal from leaking bacterial contents to the surrounding periapical tissue, i.e. the periodontal ligament $(\mathrm{PL})$ and the alveolar bone (AB). A retrograde root-end filling material must provide an apical obturation, be nontoxic, non-resorbable, stable and biocompatible [1]. Four retrograde root-filling materials are tested in clinical studies in our unit, analyzing their healing capabilities. Our clinical results from intermediate restorative material (IRM) and gutta-percha (GP) and reinforced zinc oxide (Super-EBA) have been published previously [2-4], and the results for MTA are waiting due to an ongoing study.

Root-end resection procedures entail the creation of an osteotomy site, which normally has an uneventful healing process. However, a clinical study by Vaishnavi et al. [5] indicated faster healing after retrograde root treatment if the resection defects were filled with PRP and Hydroxyapatite compared to empty controls. The use of xenografts, Bio-Oss ${ }^{\mathbb{B}}$ in combination with a resorbable 
collagen membrane, BioGide ${ }^{\circledR}$, in periradicular procedures has a reported beneficial effect on healing of apicomarginal defects [6]. Taschieri et al. [7] used the same combination for larger periradicular defects of endodontic origin only. Their study revealed no advantage on the healing outcome when using Bio-Oss ${ }^{\circledR}$ and Bio-Gide ${ }^{\circledR}$. Periapical lesions with a size of $0.5-2 \mathrm{~cm}$ in 20 patients were included in a comparable study from Sreedevi et al., where a conventional technique versus use of hydroxyapatite granules grafts into the bony defects was evaluated. They concluded that hydroxyapatite can facilitate the bone regeneration after periapical surgery procedures [8]. Insertion of bioactive glass (PerioGlas ${ }^{\mathbb{Q}}$ ) into the bone defect has been used as bone substitute in a retrospective study by Pantchev and co-workers. They concluded that bioactive glass has no significant impact on the healing of the periradicular tissue [9]. The aims of the current study were to determine whether the bone formation and the restoration of the buccal aspect of the osteotomy can be improved by filling the osteotomy defect after retrograde root canal filling with autogenous bone, which is widely accepted as the gold standard for the treatment of bone defects, or bone graft substitutes $[10,11]$. The tissue response after periapical surgery with an IRM root-end filling in combination with grafting materials was determined by a semi quantitative assessment of the inflammatory reaction and newly formed bone.

\section{MATERIALS AND METHODS}

This study was approved by the Brazilian Institute for Protection of the Environment (IBAMA) and approved by the Animal Ethic Committee at the Faculty of Dentistry of the University of the State of São Paulo-UNESP, Aracatuba, Brazil.

The study was undertaken in collaboration with the Department of Oral \& Maxillofacial Surgery and Periodontics, Faculty of Dentistry of Ribeirão Preto, University of São Paulo, Ribeirão Preto, Brazil. The study was financed by a grant from Landstinget Halland research fund. All tested bone substitute materials were offered free of charge by the manufacturers.

Six healthy adult mongrel dogs were used in this study. Their weight differed between 19 and 22 kilograms and all received tranquilization using Acepran 0.2\% (Univet, Campinas, Brazil) (acepromazine) $1 \mathrm{ml} / 10 \mathrm{~kg}$. Induction was performed with Zoletil 50 (tiletamine, zolazepam; Virbac of Brazil, Brazil) $0.12 \mathrm{ml} / \mathrm{kg}$ and the anaesthetic was maintained with Isothane (isoflurane; Baxter, Brazil) and oxygen $(30 \mathrm{ml} / \mathrm{kg})$ through an endotracheal tube.

\subsection{Surgical Procedure}

As a local hemostasis, $1.8 \mathrm{ml}$ Xylocaine $2 \%$ with adrenaline was injected into the surgical area. In each one of the animals, 5 roots in the second, third and fourth premolars in the left mandible and the mesial root the third premolar in the right mandible (empty osteotomy site control), were used for the apicectomy procedures. A mucoperiosteal buccal flap was raised over the area of the second, third and fourth premolars. The apical part of the roots and the surrounding hard tissue were removed with a round bur. The defects had a diameter of $5 \mathrm{~mm}$. The root canals were prepared with an ultrasonic preparation technique about $3 \mathrm{~mm}$ up into the root canals. All preparations were performed under constant saline irrigation. The bone cavities were packed with gauze soaked with $1 \%$ adrenaline to achieve hemostasis during the filling of the root canals. The root canals were cleaned and dried with paper points soaked in $70 \%$ alcohol. IRM was handspatulated on glass plates before applying it into the root canals. After root canal filling, each bone defect of the left mandible was filled with 1 of the 4 tested bone graft materials: CERAMENTTM|BONE VOID FILLER, (BONESUPPORT AB, Lund, Sweden, calcium sulphate $60 \%$ and hydroxyapatite $40 \%$ mixed with Iohexol); ChronOS $^{\circledR}$, (Synthes GmbH, Oberdorf, Switzerland, beta-tricalciumphosphate granules $0.7-1.4 \mathrm{~mm}, 60 \%$ porosity); Tigran ${ }^{\mathrm{TM}}$ PTG: (Porous Titanium Granules) $80 \%$ air and $20 \%$ pure titanium (Tigran technologies $\mathrm{AB} \cdot \mathrm{Medeon}$ science park, Malmö, Sweden); Easygraft ${ }^{\circledR}$, CLASSIC: Pure phase betatricalcium phosphate $(>99 \%)$ (Degradable Solutions AG, Schlieren, Switzerland). One bone defect was filled with particulated autogenous bone collected with a safescraper (Safe scraper ${ }^{\mathbb{B}}$ Biomet 3i, Warsaw, Indiana, USA) from the lateral border of the mandible. In the right mandible the defect was left to be filled with a blood clot. The flap was sutured with a resorbable suture, Vicryl ${ }^{\circledR}$ 4-0.

\subsection{Postoperative Care}

Postoperatively the animals received antibiotics, Stomorgil 10 (spiramycin, metronidazole; Merial, Brazil), $1 \mathrm{mg} / \mathrm{kg}$ daily for 10 days. Anti-inflammatory drug Maxican (meloxicam, Ouro Fino, Ribeirao Preto, Brazil), $1 \mathrm{mg} / 10 \mathrm{~kg}$ was given daily for 5 days and the analgesic Tramal 50 (tramadol hydrochloride; Pfizer, Sao Paulo, Brazil) 1 to 4 $\mathrm{mg} / \mathrm{kg}$ was injected subcutaneously every 8 hours for 3 days.

\subsection{Sacrifice, Sample Harvesting and Histological Preparation}

After 120 days the animals were sacrificed. They were anesthetized with intravenously administered sodium thiopental at a dose of $25 \mathrm{mg} / \mathrm{kg}$. After confirmation of a fully anesthetized animal, perfusion of potassium chloride to $19.1 \%$ at a dose of $1 \mathrm{ml} / \mathrm{kg}$ was performed until there was no pupillary reflex and cardiorespiratory arrest. 
The mandibles were then harvested as whole and fixed in formalin for one month before dissection. Each root with the surrounding tissue was resected from the mandible en bloc.

The blocks were dehydrated in a graded series of ethanol and embedded in resin (Technovit 7200 VCL, Kulzer, Wehrheim, Germany) during 60 days. The blocks with the embedded roots had radiographs performed in both mesial-distal and buccal-lingual projection.

One central section was cut through the long axis of the root by means of Exact cutting and grinding equipment (Exact Apparatebau, Norderstedt, Germany). The sections were ground to a final thickness of about $10 \mu \mathrm{m}$ and stained with $1 \%$ toluidine blue and $1 \%$ pyronin-G.

\subsection{Histological Analysis}

The sections were analyzed using a light microscope (Leica ${ }^{\circledR}$ DMD108). Inflammatory infiltration in the periapical area was assessed semi-quantitatively according to a 3-grade scale: none or a few areas with inflammatory cells $(+)$, some inflammatory cells within the apectomized apical area $(++)$ or a major infiltration in the apectomized area $(+++)$. In order to determine whether bone grafting leads to superior bone infill in the former resection osteotomy, the minimal and maximal distance from the surface of the retrograde root-filling material to the adjacent apical bone was measured and the mean distances was calculated. It was further evaluated whether newly formed bone was present and whether the buccal osteotomy was completely filled with bone.

\subsection{Statistical Analysis}

Kruskal-Wallis and Mann-Whitney tests were performed regarding differences in distances between the bone infill border and the retrograde root-filling surfaces and inflammatory infiltration grades.

\section{RESULTS}

All dogs received a normal diet within 24 hours of the surgical procedures. No abnormal behavior was noted. Clinical wound healing was uneventful. Thirty-four sections were included in the analysis process, 6 in each group, except for $\mathrm{ChronOs}^{\circledR}$ and Tigran ${ }^{\mathrm{TM}}$ for which 5 sections were available for analysis after the ground sectioning.

\subsection{Histology}

The experimental area typically comprised soft tissue, root, IRM, residual and newly formed bone. No evidence of remaining graft material was noted in any of the sections except for Tigran ${ }^{\mathrm{TM}}$. New bone formation and bone remodelling were seen at the recipient site. Bone was also formed in the empty control defects (Figure 1). The bone consisted of scanty mineralized bone with marrow spaces. In the non-bony periapical area mainly connective tissue was seen (Figure 2). The mean distances from the IRM surface to the adjacent apical bone were between 522.9 and $1542 \mathrm{~mm}$ and the mean values of inflammatory infiltration revealed a variation between 1 to 2.17 (Table 1). No hard-tissue formation adjacent to the IRM material could be seen in any of the specimens. All cases in the ChronOs and the empty control groups showed complete re-establishment of the buccal cortical plate (Figure 3). For the other test groups there were

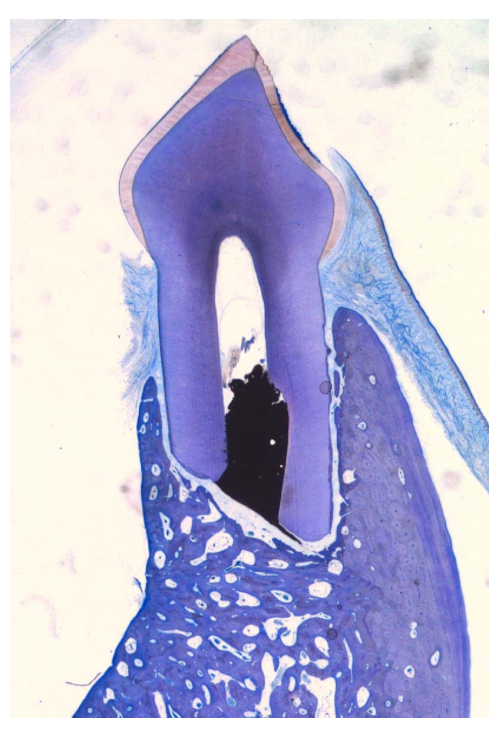

Figure 1. Empty control case showing complete bone reformation (Leica $^{\mathbb{B}}$ DMD108 2×).

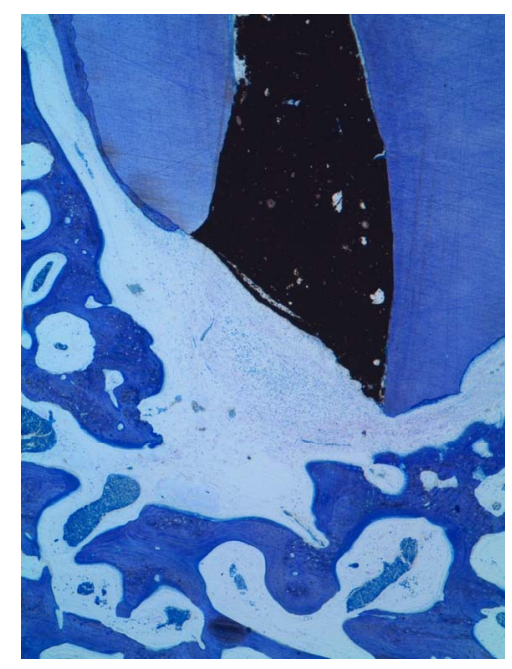

Figure 2. Cerament case showing moderate inflammatory infiltration in the connective tissue adjacent to the IRM surface (Leica ${ }^{\mathbb{B}}$ DMD108 $4 \times$ ). 
Table 1. Mean values from the histological findings for all analyzed material sections $(\mathrm{n}=34)$. Maximum (max), minimum (min) and average distance between the retrograde root-filling IRM and the alveolar bone.

\begin{tabular}{cccccc}
\hline Mtrl. & $\begin{array}{c}\text { Max } \\
(\mu \mathrm{m})\end{array}$ & $\begin{array}{c}\text { Min } \\
(\mu \mathrm{m})\end{array}$ & $\begin{array}{c}\text { Mean } \\
(\mu \mathrm{m})\end{array}$ & $\begin{array}{c}\text { Inflammatory } \\
\text { score }\end{array}$ & $\begin{array}{c}\text { Percent }(\%) \\
\text { re-established } \\
\text { buccal bone }\end{array}$ \\
\hline EasyGraft $(\mathrm{n}=6)$ & 802.7 & 329.3 & 566.0 & 1.33 & 83.3 \\
ChronOS $(\mathrm{n}=5)$ & 671.4 & 374.4 & 522.9 & 1.40 & 100 \\
Cerament $(\mathrm{n}=6)$ & 1705 & 1379 & 1542 & 2.17 & 66.7 \\
Tigran $(\mathrm{n}=5)$ & 1047 & 602.2 & 824.6 & 1.80 & 60.0 \\
Part. bone $(\mathrm{n}=6)$ & 1065 & 348.0 & 706.5 & 1.00 & 83.3 \\
Empty control $(\mathrm{n}=6)$ & 773.0 & 370.0 & 571.5 & 1.50 & 100 \\
\hline
\end{tabular}

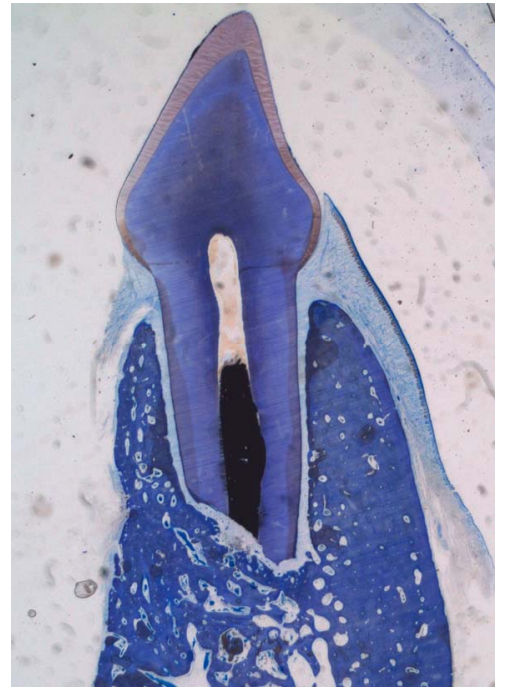

Figure 3. ChronOs case showing complete bone healing with reestablishment of the buccal cortical plate (Leica ${ }^{\circledR}$ DMD108 2×).

cases showing incomplete healing of the buccal cortical plate (Table 1).

\subsection{Statistical Analysis}

There was no statistical significant difference between the materials/bone for the 2 tested parameters when comparing all groups. When comparing two groups to each other there was a significant difference between Chron$\mathrm{Os}^{\circledR}$ and CERAMENT ${ }^{\mathrm{TM}} \mid$ BONE VOID FILLER, regarding the bone border-IRM surface distance $(p=0.044)$ and between particulated bone and Cerament regarding the inflammatory grade $(\mathrm{p}=0.021)$.

\section{DISCUSSION}

In this study root-end resection with retrograde IRM root-filling was performed on vital teeth in six dogs. The resection osteotomy was filled with either autogenous bone, bone graft substitutes: CERAMENT ${ }^{\mathrm{TM}} \mid \mathrm{BONE}$ VOID FILLER, ChronOS $^{\circledR}$, Tigran $^{\text {TM }}$ PTG, Easygraft ${ }^{\circledR}$, or was left empty. The healing time was four months, which corresponds to a healing period of six months in man. In all cases, newly formed bone was detected at the site of the former osteotomy. The present data analysis does not include histomorphometric analysis to quantify the amount of newly formed bone in the former defect. However, within the scope of this analysis, no statistical difference could be detected between the tested groups, suggesting that filling of the defect did not enhance healing. According to these results the clinical significance of the use of infill of the osteotomy defects in periapical surgery might be questionable. One reason for the outcome from the present study might be that the prepared defects in the bone were of sub-critical size and five walls, which allows for spontaneous healing of the defect. Isaksson et al. [10] created skull defect on rabbits with a trephine burr and showed no difference in healing pattern comparing bone chips graft or empty control. However, Klinge et al. [11] prepared rabbit skull defects and showed initial faster bone regeneration after 4 weeks of healing when using resorbable hydroxyapatite compared to an empty control, but there was no difference detected between the treatments after 14 weeks. The rabbit data suggest that bone grafting may have favored early bone formation in the present dog study, which is not detectable since only a late time point (120 days) was analyzed. I cases with bone defects missing both the buccal and lingual cortical plates, the use of a bone substitute may be beneficial on the healing, similar to the use of porous membranes in periapical defects [12]. The use of membrane and BioOss [13] and calcium sulphate [14] in through and through periapical lesions, has also shown in clinical studies to improve the clinical healing outcome. No statistically significant difference was revealed in terms of inflammatory reactions when comparing all tested groups. In the present study, there was a minor inflammatory cell response noted in three of the empty control sites, two of the sites treated with easygraft and one with ChronOs material. Three of the CERAMENT $^{\mathrm{TM}} \mid$ BONE VOID FILLER sites showed a major infiltration which can indicate an ongoing healing 
process and the result may have been altered in a longer healing time due to the compositon of the material [15]. The significant difference in healing results from the present study between CERAMENT ${ }^{\mathrm{TM}} \mid$ BONE VOID FILLER and ChronOs might be explained by the HA and TCP content respectively. Jensen et al. concluded in an experimental study, that the amount of bone formation was inversely proportional to the HA/TCP ratio [16]. CERAMENT ${ }^{\mathrm{TM}} \mid$ BONE VOID FILLER used in an intraoral environment has the proposed capacity to guide bone generation from a surface of intact cortical bone [17]. There were only $60 \%$ of the Tigran cases which showed complete re-establishment of the buccal cortical defect, which can be explained by that Tigran granules may need a longer healing period like in CERA-

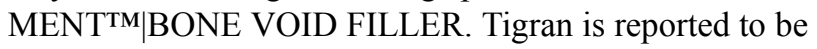
osteoconductive in experimental osseous defects in conjunction with titanium implants [18]. The retrograde material in this experiment was intermediate restorative material, IRM and it has been reported to be a suitable rootend filling material in periapical surgery procedures $[4$, 19]. IRM has a good tissue response when it comes to bone healing similar to mineral trioxide aggregate, MTA. MTA also revealed the ability of hard tissue growth on material surface [20]. This difference could have affected the present study outcome, if MTA would have been used as the retrograde filling material. This is in line with a study from Favieri and co-workers who reported that the use of MTA in combination bone-substitute in large bony defect can benefit the healing outcome [21]. The mean distance between the root-end filler and the bone among the groups (Table 1), thus the size of the zone without hard tissue seems not to depend on whether the resection defect has been filled or not. Complete sealing by the root end filling is vital for a success, and already minor leakage may trigger inflammatory responses and may inhibit hard tissue formation in the proximity of the sealed root canal. Furthermore, eugenol leaching from IRM and Super-EBA is also known to affect the surrounding periapical tissue by eliciting a minor inflammatory response. This reaction has been discussed in a study by Wälivaara et al. [20], where different retrograde filling materials have been used without bone grafting. Also, healing may be influenced by the chewing forces, which may cause a slight displacement of the short, apectomized roots.

No foreign body reaction was detected against the bone-substitute materials, and efficient bone healing was noted in the area further away from the IRM filling thus confirming the biocompatibility of the bone graft substitutes. No remnants of the bone graft substitutes except for Tigran ${ }^{\mathrm{TM}}$ PTG, were detected in the histological sections, which argues for a complete degradation of the other materials within the study period.

\section{CONCLUSION}

In conclusion the healing outcome after periapical surgery in a five-wall resection defect could not be increased by infill of autogenous bone or bone graft substitutes. Thus, the most important factor for the healing outcome in periapical surgery is the quality of the rootend sealing. The healing outcome after some of the tested bone substitute materials, might be improved by longer healing time.

\section{REFERENCES}

[1] Chong, B.S. and Pitt Ford, T.R. (2005) Root-end filling materials: Rationale and tissue response. Endodontic Topics, 2005, 114-130.

doi:10.1111/j.1601-1546.2005.00164.x

[2] Walivaara, D.A., Abrahamsson, P., Isaksson, S., Blomqvist, J.E. and Samfors, K.A. (2007) Prospective study of periapically infected teeth treated with periapical surgery including ultrasonic preparation and retrograde intermediate restorative material root-end fillings. Journal of Oral and Maxillofacial Surgery, 5, 931-935. doi:10.1016/i.joms.2005.12.077

[3] Walivaara, D.A., Abrahamsson, P., Samfors, K.A. and Isaksson, S. (2009) Periapical surgery using ultrasonic preparation and thermoplasticized gutta-percha with $\mathrm{AH}$ Plus sealer or IRM as retrograde root-end fillings in 160 consecutive teeth: A prospective randomized clinical study. Oral Surgery, Oral Medicine, Oral Pathology, Oral Radiology and Endodontics, 5, 784-789.

doi:10.1016/j.tripleo.2009.06.010

[4] Walivaara, D.A., Abrahamsson, P., Fogelin, M. and Isaksson, S. (2011) Super-EBA and IRM as root-end fillings in periapical surgery with ultrasonic preparation: A prospective randomized clinical study of 206 consecutive teeth. Oral Surgery, Oral Medicine, Oral Pathology, Oral Radiology and Endodontics, 2, 258-263.

doi:10.1016/j.tripleo.2011.01.016

[5] Vaishnavi, C., Mohan, B. and Narayanan, L.L. (2011) Treatment of endodontically induced periapical lesions using hydroxyapatite, platelet-rich plasma, and a combination of both: An in vivo study. Journal of Conservative Dentistry, 2, 140-146. doi:10.4103/0972-0707.82614

[6] Dietrich, T., Zunker, P., Dietrich, D. and Bernimoulin, J.P. (2003) Periapical and periodontal healing after osseous grafting and guided tissue regeneration treatment of apicomarginal defects in periradicular surgery: Results after 12 months. Oral Surgery, Oral Medicine, Oral Pathology, Oral Radiology and Endodontics, 4, 474-482. doi: $10.1067 /$ moe.2003.39

[7] Taschieri, S., Del Fabbro, M., Testori, T. and Weinstein, R. (2007) Efficacy of xenogeneic bone grafting with guided tissue regeneration in the management of bone defects after surgical endodontics. Journal of Oral and Maxillofacial Surgery, 6, 1121-1127. doi:10.1016/j.joms.2006.10.022

[8] Sreedevi, P., Varghese, N. and Varugheese, J.M. (2011) 
Prognosis of periapical surgery using bonegrafts: A clinical study. Journal of Conservative Dentistry, 1, 68-72. doi:10.4103/0972-0707.80743

[9] Pantchev, A., Nohlert, E. and Tegelberg, A. (2009) Endodontic surgery with and without inserts of bioactive glass PerioGlas-A clinical and radiographic follow-up. Oral and Maxillofacial Surgery, 1, 21-26.

[10] Isaksson, S., Alberius, P., Klinge, B. and Jonsson, J. (1992) Contribution of autogeneic membranous bone chips and bone paste to healing of rabbit skull defects. Scandinavian Journal of Dental Research, 5, 274-278.

[11] Klinge, B., Alberius, P., Isaksson, S. and Jonsson, J. (1992) Osseous response to implanted natural bone mineral and synthetic hydroxylapatite ceramic in the repair of experimental skull bone defects. Journal of Oral and Maxillofacial Surgery, 3, 241-249. doi:10.1016/0278-2391(92)90320-Y

[12] Dahlin, C., Gottlow, J., Linde, A. and Nyman, S. (1990) Healing of maxillary and mandibular bone defects using a membrane technique. An experimental study in monkeys. Scandinavian Journal of Plastic and Reconstructive Surgery and Hand Surgery, 1, 13-19.

[13] Taschieri, S., Del Fabbro, M., Testori, T., Saita, M. and Weinstein, R. (2008) Efficacy of guided tissue regeneration in the management of through-and-through lesions following surgical endodontics: A preliminary study. The International Journal of Periodontics \& Restorative Dentistry, 3, 265-271.

[14] Pecora, G., De Leonardis, D., Ibrahim, N., Bovi, M. and Cornelini, R. (2001) The use of calcium sulphate in the surgical treatment of a "through and through" periradicular lesion. International Endodontic Journal, 3, 189-197. doi:10.1046/j.1365-2591.2001.00369.x

[15] Nilsson, M., Wang, J.S., Wielanek, L., Tanner, K.E. and Lidgren, L. (2004) Biodegradation and biocompatability of a calcium sulphate-hydroxyapatite bone substitute. The
Journal of Bone and Joint Surgery, British Volume, 1 , 120-125.

[16] Jensen, S.S., Bornstein, M.M., Dard, M., Bosshardt, D.D. and Buser, D. (2009) Comparative study of biphasic calcium phosphates with different HA/TCP ratios in mandibular bone defects. A long-term histomorphometric study in minipigs. Journal of Biomedical Materials Research Part B: Applied Biomaterials, 1, 171-181.

[17] Truedsson, A., Wang, J.S., Lindberg. P., Gordh. M., Sunzel, B. and Warfvinge, G. (2010) Bone substitute as an on-lay graft on rat tibia. Clinical Oral Implants Research, 4, 424-429. doi:10.1111/j.1600-0501.2009.01875.x

[18] Wohlfahrt, J.C., Monjo, M., Ronold, H.J., Aass, A.M., Ellingsen, J.E. and Lyngstadaas, S.P. (2010) Porous titanium granules promote bone healing and growth in rabbit tibia peri-implant osseous defects. Clinical Oral Implants Research, 2, 165-173. doi:10.1111/j.1600-0501.2009.01813.x

[19] Chong, B.S., Pitt Ford, T.R. and Hudson, M.B. (2003) A prospective clinical study of Mineral Trioxide Aggregate and IRM when used as root-end filling materials in endodontic surgery. International Endodontic Journal, 8, 520-526. doi:10.1046/j.1365-2591.2003.00682.x

[20] Walivaara, D.A., Abrahamsson, P., Isaksson, S., Salata, L.A., Sennerby, L. and Dahlin, C. (2012) Periapical tissue response after use of intermediate restorative material, gutta-percha, reinforced zinc oxide cement, and mineral trioxide aggregate as retrograde root-end filling materials: a histologic study in dogs. Journal of Oral and Maxillofacial Surgery, 9, 2041-2047. doi:10.1016/j.joms.2012.01.033

[21] Favieri, A., Campos, L.C., Burity, V.H., Santa Cecilia, M. and Abad Eda, C. (2008) Use of biomaterials in periradicular surgery: A case report. Journal of Endodontics, 4, 490-494. doi:10.1016/j.joen.2008.01.012 